\title{
1 Precision and Accuracy in Geochronology
}

2

3 Blair Schoene ${ }^{1}$, Daniel J. Condon ${ }^{2}$, Leah Morgan ${ }^{3}$, and Noah McLean ${ }^{2}$

4 1. Department of Geosciences, Princeton University, Princeton, New Jersey 08544, USA

5 2. NERC Isotope Geosciences Laboratory, British Geological Survey, NG12 5GG, UK

6 3. Scottish Universities Environmental Research Centre, East Kilbride, G75 0QF, UK

7

\section{Abstract/Summary}

9 There is an increasing demand for geochronology in Earth and solar system science, and this 10 demand is not only for more, but for higher precision, more accurate, and more easily 11 interpreted temporal constraints. Because modern research often requires multiple dating 12 methods, scrupulous inter- and intra-method calibration in absolute time is required.

13 However, improved precision has highlighted systematic analytical biases and uncovered 14 geologic complexity that affects mineral dates. At the same time, both enhanced spatial 15 resolution through microbeam geochronology and creative uses of disparate datasets to 16 inform age interpretations have helped explain complexities in age data. Quantifying random 17 and systematic sources of instrumental and geological uncertainty is vital, and requires 18 transparency in methodology, data reduction, and reporting. Community efforts toward inter19 and intra-calibration of chronometers will continue to help achieve the highest possible 20 resolving power for integrative geochronology. 


\section{1. The importance of precision and accuracy}

Few if any scientific disciplines publish numerical data that are accepted by non-experts and propagated through the literature as extensively as ages determined by geochronology. Radioisotopic dates are used to constrain the age of a wide variety of rocks and mineral types, from 4.4 billion year old zircons to volcanic eruptions and corals only a few tens to hundreds of years old. Driven by increasingly intricate geological questions and a more complete geologic time scale, more precise and accurate time constraints are required through integrating multiple analyses from different laboratories using different decay schemes. Of paramount importance, therefore, is that reported dates are of adequate precision and accuracy to answer the question asked. But how do we distinguish precision from accuracy in geochronology, and how do we use these terms quantitatively? In this article we attempt to outline "where radioisotopic dates come from"-their foundation in metrology, mass spectrometry, chemistry, and physics, and show how measurement and geologic uncertainty propagate into age interpretations.

Radioisotopic methods capitalize on radioactive decay of parent to daughter nuclides. Though the sources of uncertainty and the calculation of dates vary for each dating method, we highlight below some key generic themes common to many dating methods. Terminology is important and often the terms precision, accuracy, and uncertainty are used loosely in the geological literature even though strict definitions are used in the metrology and analytical chemistry communities (e.g., Potts, 2012). Definitions for precision, accuracy and uncertainty are given in the Glossary of Useful Terms (Page XX) and Fig. 1 illustrates their common usage in geochronology. Precision is one component of uncertainty, where higher precision measurements are more repeatable and reproducible. Accuracy, another component of uncertainty, expresses how close a measurement comes to the true value (Fig. 1).

When considering uncertainties in radioisotope geochronology, it is often useful to differentiate between 'systematic' and 'random' uncertainties. Systematic uncertainties are constant or skew results in a predictable way such that they affect accuracy. The best example of systematic uncertainties comes from decay constants. In contrast, random uncertainties vary in an unpredictable manner, usually with an assumed Gaussian distribution, and would include analytical uncertainties in isotope ratio mass spectrometry. With unlimited time and sample, repeat measurements could reduce random uncertainties to zero, but systematic effects would remain.

Differentiating between random and systematic uncertainties is important, so that one can confidently answer the question "are these two dates really different from one another?" For example, to quantify the time difference between two samples dated by one method, say U$\mathrm{Pb}$, we can ignore decay constant uncertainties that would bias both ages in the same predictable manner. If however, we wanted to compare two dates, one $\mathrm{Rb}-\mathrm{Sr}$ and one ${ }^{40} \mathrm{Ar} /{ }^{39} \mathrm{Ar}$, we must incorporate the decay constant uncertainties of both systems so as to not mistake inter-chronometer bias for a real age difference (see Text Box). 
Field observations can be used to establish relative time constraints for geologic events through stratigraphic analysis or using cross-cutting relationships. Geochronology, however, provides what are often referred to as "absolute" time constraints. Absolute dates are ones that can be traced to standard units (e.g. kilogram, Becquerel) through a series of metrological experiments (traceability). This allows quantification of systematic uncertainties and permits comparison of radioisotopic dates to chronologies based upon independent temporal proxies. For example, U-Th dates that are calibrated against metrologically traceable standards and the $\mathrm{U}$ and Th decay constants (see below) can be meaningfully compared to independently derived models of solar insolation as a means to assess potential cause and effect between drivers of ice sheet volume change and sea-level (e.g., Cutler et al., 2003).

Many geochronologists distinguish the terms date and age. A date is a number calculated using measured isotopic ratios and the decay equation, and a date becomes an age when geologic significance is attached to that number. Correctly reporting a date as an age thus depends on accurate interpretation of radioisotopic data, which is not easy given the complicated nature of geologic processes. Over the past several decades, analyses employing new technology with increasing spatial resolution have revealed intra-mineral isotopic variability important for interpreting mineral dates. Recognition of millimeter- to micrometer-scale isotopic variation has inspired microsampling (e.g. microdrilling) and insitu 'microbeam' techniques (primarily SIMS and LA-ICP-MS; Nemchin et al., this volume). These methods offer the potential for more informed sampling and coupling with geochemical and textural data and thus contribute to more accurate age interpretations. During this same period of time, precision in some lower-spatial resolution techniques (i.e., those that require manual manipulation and/or dissolution) has improved from several percent to less than a permil on single dates (e.g. \pm 3 Myr to $\pm 100 \mathrm{kyr}$ for a $100 \mathrm{Ma}$ sample). As a result, systematic biases now often dominate uncertainty in comparisons between dating methods and between laboratories. Improving values of physical constants, such as decay constants, and verification of measured unknowns by analysis of reference materials, has become increasingly important.

Comparing and integrating dates from different dating methods thus requires incorporation of geochemical and isotopic data with stratigraphic and field data. In other words, understanding complex geologic systems requires relating each date to a process, which results in an exciting interplay between scientists from nearly all realms of geosciences.

\section{Determining parent/daughter isotope ratios (mass spectrometry)}

A date $(t)$ for a mineral or rock can be calculated using the age equation if one determines the atomic ratio of a stable daughter isotope relative to its radioactive parent isotope $(D / P)$, and the parent isotope's decay constant $(\lambda)$.

$$
\text { Age equation: } \frac{D}{P} \div=\exp (t) \quad 1
$$


These two inputs, and their accuracy and precision, control the accuracy and precision of radioisotopic dates. Determining the ratio of daughter products to their parent isotopes is the field of isotope ratio mass spectrometry and isotope geochemistry, and the principles and methods for achieving this are covered in many textbooks (e.g., Faure and Mensing, 2005).

In brief, determining accurate $D / P$ ratios using isotope ratio mass spectrometry is complicated for several reasons, including: (1) differential ionization of isotopes from different elements (i.e., $\mathrm{U}$ and $\mathrm{Pb}, \mathrm{Re}$ and $\mathrm{Os}$ ); (2) fractionation of the $\mathrm{D} / \mathrm{P}$ ratio during ion exchange chemistry (employed to purify an element prior to mass-spectrometry); (3) mass dependent fractionation of different isotopes during mass spectrometry; (4) correction for non-radiogenic $D$, namely that the measured sample may contain not only the daughter isotope derived from the decay of the parent, but also $D$ that is within the material when it formed and/or introduced during sample processing in the laboratory; and (5) traceability of age standards employed by some methods (e.g., ${ }^{40} \mathrm{Ar} /{ }^{39} \mathrm{Ar}$ ). Each of these factors can contribute to inaccurate dates, depending on the nature of the material being analyzed, the type of mass spectrometer, and radioisotopic method being used.

117 Tracing $D / P$ back to first principles measurements can be done accurately provided systematic and random uncertainties are carefully accounted for. In order to effectively eliminate fractionation of $D / P$ during chemical purification of a sample and/or isotope ratio mass spectrometry, a method termed isotope dilution is employed. This involves adding to the sample synthetic or highly enriched tracer isotopes $\left(\mathrm{T}_{\mathrm{D}}\right.$ and $\left.\mathrm{T}_{\mathrm{P}}\right)$ of the $D$ and $P$ elements, with precisely determined $\mathrm{T}_{\mathrm{D}} / \mathrm{T}_{\mathrm{P}}$ (e.g. ${ }^{205} \mathrm{~Pb}$ and ${ }^{233} \mathrm{U}$ tracers added to a sample targeted for $\mathrm{U}-\mathrm{Pb}$ dating) prior to any procedures that could result in $D / P$ fractionation. As the sample is processed and $D / P$ fractionates in the laboratory, $\mathrm{T}_{\mathrm{D}} / \mathrm{T}_{\mathrm{P}}$ also fractionates in exactly the same way. Therefore knowledge of $\mathrm{T}_{\mathrm{D}} / \mathrm{T}_{\mathrm{P}}$ allows determination of $D / P$, even if the isotope ratio measurements of $D$ and $P$ are carried out using different methods and/or at different times. A critical link in the traceability chain is the calibration of these tracers, and this is done in a similar manner, this time treating $\mathrm{T}_{\mathrm{D}}$ and $\mathrm{T}_{\mathrm{P}}$ as unknowns and mixing them with a gravimetric reference solution (Cheng et al., 2000; Wasserburg et al., 1981). These solutions are made by dissolving large amounts of precisely and accurately weighed high-purity reference material (typically salts or metals) of the $D$ and $P$ elements such that their elemental ratio is known relative to the kilogram.

Isotope dilution requires the tracer isotopes to be mixed and equilibrated with the sample; therefore this approach cannot be used on analytical methods that directly analyze a solid material, such as the in situ microbeam methods that use a laser or ion beam to remove material from a solid sample. These methods derive their accuracy by determining $D / P$ relative to a standard material, commonly a mineral that has homogenous and known $D / P$. Thus, 'relative dating' methodologies depend on a the reference material whose $D / P$ can be known by isotope dilution (e.g., Wiedenbeck et al., 1995).

\section{From isotope ratios to time (decay constants)}

142 The absolute accuracy of radioisotopic geochronometers universally depends on the decay 
constant of the parent isotope in the age equation. Some systems rely on decay constants for multiple isotopes; others rely on branched decays, where a single parent isotope has multiple daughter isotopes. Other physical constants are important in some decay schemes, in particular natural isotopic ratios. For example, $\mathrm{U}-\mathrm{Pb}$ dating often relies, in part, on assuming a natural and constant ${ }^{238} \mathrm{U} /{ }^{235} \mathrm{U}$ ratio, while the ${ }^{40} \mathrm{Ar} /{ }^{39} \mathrm{Ar}$ system relies on the atmospheric ${ }^{40} \mathrm{Ar} /{ }^{36} \mathrm{Ar}$ ratio to differentiate radiogenic ${ }^{40} \mathrm{Ar}$ from atmospheric ${ }^{40} \mathrm{Ar}$, as well as the natural ${ }^{40} \mathrm{~K} /{ }^{39} \mathrm{~K}$ ratio.

Determining decay constants is a non-trivial task, and several methods can be used. Direct determination by activity counting (measuring energy resulting from radioactive decay as a function of time, e.g., Beckinsale and Gale, 1969; Jaffey et al., 1971) or ingrowth experiments using isotopically enriched materials (measuring the moles of $D$ produced relative to $P$ over a known length of time, e.g., Rotenberg et al., 2012) have been used to measure $\lambda$ with traceability to standard units. Due to the long half-life of most radioactive isotopes useful for geochronology, these experiments are difficult and measurements of different decay constants may have order-of-magnitude differences in their experimental uncertainties.

An alternative approach is inter-calibration, where the accuracy of one system can be exported to another system by selecting minerals or rocks that 1) are amenable to highprecision geochronology using multiple methods and 2) are relatable to a set of processes that occurred at the same time, for example crystallization of two minerals immediately prior to a volcanic eruption or rapid crystallization and cooling beneath Earth's surface. The result is that one can compare dates from different techniques (e.g., U-Pb zircon and ${ }^{40} \mathrm{Ar} /{ }^{39} \mathrm{Ar}$ sanidine) with uncertainties that are smaller than the decay constant experiments. Typically, intercalibration experiments exploit the most precisely determined decay constant $\lambda^{238} \mathrm{U}$, with an uncertainty of $\pm 0.11 \%$ ( $2 \sigma$; Jaffey et al., 1971). For example, the analyses of closed system minerals, such as zircon, have been used to improve the accuracy of the other $U$ and Th decay constants: $\lambda^{238} \mathrm{U} / \lambda^{235} \mathrm{U}$, (Mattinson, 2010; Amelin and Zaitsev, 2002) and $\lambda^{238} \mathrm{U} /$ $\lambda^{234} \mathrm{U}$ and $\lambda^{238} \mathrm{U} / \lambda^{230} \mathrm{Th}$ (Cheng et al., 2000; Ludwig et al., 1992). Coeval or relatable mineral pairs have also been used in calibrations of other decay constants, such as $\lambda^{187} \operatorname{Re}$ 173 2001).

Though decay constants determined by intercalibration of different decay schemes provide a means to enhance the relative accuracy of dates, we must recognize that such systems are no longer independent measurements. In practical terms, the accuracy of a system intercalibrated with $\lambda^{238} \mathrm{U}$ is limited by the accuracy of the $\mathrm{U}-\mathrm{Pb}$ system. The resulting covariance between dates means that systematic uncertainties in the U-Pb system propagate through every other system. These contributions include the original experiments used to determine the U decay constants (Jaffey et al., 1971), the isotopic composition of uranium (Hiess et al., 2012), and also the standard reference materials used in tracer calibration and related experiments (see above). radiometric means of determining geologic time, such as astrochronology, which relies on 
cyclic climate records preserved in sedimentary rocks as an absolute clock. Intercalibration of radiometric clocks with time estimates from astrochronology have been highly successful (Kuiper et al., 2008), but have also revealed disparities likely created by errors in age models for sedimentary cyclicity (e.g., Westerhold et al., 2012). While researchers continue to explore the best methods to determine accurate and precise decay constants, the current situation is one where different researchers are applying different values to their measurements. This ambiguity can be confusing to the larger geological community, and therefore geochronologists must be particularly careful to state the values of the decay constants and standards used to calculate dates from isotopic ratios, and readers must also look for this information.

\section{From dates to ages (geologic interpretation)}

Transforming a date into an age requires interpreting a date calculated using the age equation to represent a specific geologic process, and this is just as important as the date's numerical accuracy and metrological traceability. Examples of interpretations of mineral dates include assigning crystallization ages in an igneous system, reporting ages of volcanic eruptions based upon dates of minerals from ash beds, associating datable minerals to ages of metamorphic events, using dates of carbonates to determine ages of low-temperature aqueous precipitation, and/or using dates to calibrate cooling beneath a certain temperature for systems where diffusion of daughter product occurs at high temperatures (see Reiners and Ehlers, 2005, for the latter example). As the questions we ask become increasingly detailed and sophisticated, and as our methods become increasingly precise, the knowledge of how a date is recorded in a mineral, or mineral sub-domain, and how that in turn relates to some other some other geological information (e.g., petrographic context, other isotope and/or geochemical information) become crucial.

Application of petrographic and micro-imaging methods for characterizing the internal structure of minerals has improved our understanding of mineral growth and rock petrogenesis. Analytical methods used for radioisotope ratio measurements tend to capitalize on either high-precision dates using isotope dilution and physical manipulation of mineral fragments (Schmitz and Kuiper, this volume), or high spatial resolution using a focused ion beam or laser, guided by imaging (Nemchin et al., this volume). A frequent point of discussion is the merits of high-spatial resolution analyses as opposed to dissolution methods, given the complimentary strengths of each method. Acknowledging that nearly all geologic samples contain some age variation (it can be argued that very few analyzed volumes represent instantaneous crystallization), what is critical is both the temporal and spatial scale of the variation (Fig. 2). In cases where a single crystal records a protracted crystallization history, say an old mineral core surrounded by a much younger overgrowth, analysis of whole minerals can result in dates that represent a mixture of different domains, and microbeam/sampling methods are preferred. However, studies that wish to measure the timescales of geologic processes that occur more quickly than can be resolved with in situ techniques, employing isotope dilution methods is necessary and one must attempt to understand the impact of averaging growth histories over a larger volume of material. There are several 
steps that can be taken in sample preparation and analysis that help geochronologists determine whether temporal or spatial resolution is more important for a given study, and thus to attain the most accurate dates possible. These are briefly outlined below.

\section{Sample characterization}

Field relationships - Despite the power of geochronology to resolve absolute time, interpreted ages must be consistent with field relationships, for example cross-cutting relationships in igneous bodies or the law of superposition in sedimentary rocks. Rock sampling strategies in well-mapped areas can discriminate between and refine hypotheses and minimize the number of samples necessary for geochronology.

Petrography - It is essential to use petrographic or mineral texture data to guide geochronologic sampling. Observations in thin section can help determine the petrogenetic history of datable minerals, for example by relating them to metamorphic reactions or equilibrium assemblages. Microbeam methods permit in situ analyses of mineral subdomains of interest.

Textural and geochemical characterization - Internal textures of the datable minerals themselves such as growth zoning can be observed using optical microscopy, or backscattered electron and/or cathodoluminescence imaging, and a scanning electron microscope is usually employed for this. Textural data can also be combined with geochemical and crystallographic data, either determined in situ prior to microbeam geochronology, or on a portion of the dissolved, dated sample. For example, XRD analysis of fossil coral is routinely employed to determine whether secondary/diagenetic calcite is present in a sample, and optical microscopy can be used to assess the presence of secondary aragonite, both of which impact the accuracy of U-Th dates.

\section{Testing for closed-system behavior}

253 Some systems offer an internal check for closed-system behavior in that they contain more

254 than one radionuclide, which means that two dates can be obtained from one mineral/rock sample. If the mineral/rock has behaved as a closed system with respect to the parent and daughter nuclides since the start of daughter in-growth, the dates should be concordant. Examples include ${ }^{238} \mathrm{U}_{-}{ }^{206} \mathrm{~Pb}$ and ${ }^{235} \mathrm{U}_{-}{ }^{207} \mathrm{~Pb}$ dates in zircon and other uranium bearing minerals (Schoene, in press), and ${ }^{235} \mathrm{U}_{-}^{231} \mathrm{~Pa}$ and ${ }^{234} \mathrm{U}_{-}{ }^{230} \mathrm{Th}$ dates in carbonate (e.g., fossil coral; Edwards et al., 2003). Other internal checks can include natural isotopic compositions that are predictable in nature when a material forms (e.g. ${ }^{234} \mathrm{U} /{ }^{238} \mathrm{U}_{\text {seawater }}$ ) but are perturbed during alteration and open-system behavior. Date reproducibility between heating steps also allows for an assessment of open-system behavior in ${ }^{40} \mathrm{Ar} /{ }^{39} \mathrm{Ar}$ analyses (McDougall and Harrison, 1999). Reproducibility between many minerals in the same sample is also a method of verifying closed-system behavior given metamorphism, daughter-product loss, and recrystallization tends to be distributed heterogeneously in single samples. 
268 It is common to apply a statistical model to a set of dates to assess reproducibility and/or to arrive at an interpreted age. The two most common models used are linear regressions (isochrons) and weighted means. Associated with these statistical models are measures of the goodness of fit, such as the mean square of weighted deviates (MSWD, also known as reduced chi-squared statistic; Wendt and Carl, 1991; York et al., 2004) or the related probability of fit. It is important to note that these measures are related to the precision of the single data points used in the statistical model: if the scatter in the single data points can be predicted by their estimated uncertainty, then the MSWD will be near unity; however if the uncertainties of the same data are much smaller than the intra-sample variation, then the MSWD or other measure will highlight the lack of coherence (Fig. 1). It is extremely important that when statistical models are used to calculate dates or assess closed system behavior, that a goodness of fit is reported, in that this helps a reader (and an author) to evaluate the accuracy of the age interpretation (Ludwig, 2003b)

\section{Summary and the future}

The complexity and abundance of studies in the Earth and meteoritic sciences requiring absolute time constraints has increased in recent years. In general, the reported precision on ages has improved, and the number of studies that integrate multiple dating methods has increased. With increased resolving power comes an increased responsibility that radioisotopic dates and their uncertainties are used appropriately; this statement applies to both researchers producing and publishing geochronologic data and to others who use these ages in their own work.

Efforts to hone decay constant and physical constant uncertainties will likely continue, as will experiments to better estimate inter- and intra-laboratory agreement. This will help geochronologists understand and quantify the various sources of random and systematic uncertainties stemming from the laboratory methods, standards and physical constants used for various decay schemes. Continued experiments tracing age determinations to standard units and better relating them to one another is crucial for our understanding of absolute uncertainty in geologic time and application to the geologic timescale.

The future of geochronology will see continued accuracy in precision of age determinations, both on single analyses and on statistical treatments of data such as weighted means. Integration of geochronologic data with geochemical, textural, and stratigraphic proxies will aid such age interpretations. Greater confidence is to be gained through the reproduction of results with different sample sets, and generation of higher fidelity datasets can help inform geologic uncertainty.

\section{References Cited}


Beckinsale, R. D., and Gale, N. H., 1969, A reappraisal of the decay constants and branching ratio of ${ }^{40} \mathrm{~K}$ : Earth and Planetary Science Letters, v. 6, no. 4, p. 289-294.

Cheng, H., Edwards, R. L., Hoff, J., Gallup, C. D., Richards, D. A., and Asmerom, Y., 2000, The half-lives of ${ }^{234} \mathrm{U}$ and ${ }^{230} \mathrm{Th}$ : Chemical Geology, v. 169, no. 1-2, p. 17-33.

Cutler, K.B., Edwards, R.L., Taylor, F.W., Cheng, H., Adkins, J., Gallup, C.D., Cutler, P.M., Burr, G.S., and Bloom, A.L., 2003, Rapid sea-level fall and deep-ocean temperature change since the last interglacial period: Earth and Planetary Science Letters, v. 206, p. 253-271.

De Bièvre, P., Dybkær, R., Fajgelj, A., and Hibbert, D. B., 2011, Metrological traceability of measurement results in chemistry: Concepts and implementation (IUPAC Technical Report): Pure and Applied Chemistry, v. 83, no. 10, p. 63.

Edwards, R.L., Gallup, C.D., and Cheng, H., 2003, Uranium-series Dating of Marine and Lacustrine Carbonates: Reviews in Mineralogy and Geochemistry, v. 52, p. 363-405.

Faure, G., and Mensing, T.M., 2005, Isotopes - Principles and Applications; 3rd edition: Hoboken, N.J., John Wiley \& Sons, Inc., 897 p.

Hiess, J., Condon, D.J., McLean and Noble, S.R., 2012, ${ }^{238} \mathrm{U} /{ }^{235} \mathrm{U}$ Systematics in Terrestrial Uranium-Bearing Minerals: Science, v. 335, p. 1610-1614.

Jaffey, A. H., Flynn, K. F., Glendenin, L. E., Bentley, W. C., and Essling, A. M., 1971, Precision measurement of half-lives and specific of ${ }^{235} \mathrm{U}$ and ${ }^{238} \mathrm{U}$ : Physics Reviews, v. C4, p. 1889-1906.

Kuiper, K. F., Deino, A., Hilgen, F. J., Krijgsman, W., Renne, P. R., and Wijbrans, J. R., 2008, Synchronizing Rock Clocks of Earth History: Science, v. 320, no. 5875, p. 500504.

Ludwig, K. R., 2003a, Mathematical-Statistical Treatment of Data and Errors for ${ }^{230} \mathrm{Th} / \mathrm{U}$ Geochronology: Reviews in Mineralogy and Geochemistry, v. 52, no. 1, p. 631-656.

Ludwig, K. R., 2003b, Isoplot/Ex Version 3.00: a geological toolkit for Microsoft Excel. Berkeley Geochronology Center Special Publication, 70pp, 4.

Ludwig, K. R., Simmons, K. R., Szabo, B. J., Winograd, I. J., Landwehr, J. M., Riggs, A. C., and Hoffman, R. J., 1992, Mass-Spectrometric ${ }^{230} \mathrm{Th}^{234}{ }^{\mathrm{U}}{ }_{-}^{238} \mathrm{U}$ Dating of the DevilsHole Calcite Vein: Science, v. 258, no. 5080, p. 284-287.

Mattinson, J. M., 2010, Analysis of the relative decay constants of ${ }^{235} \mathrm{U}$ and ${ }^{238} \mathrm{U}$ by multistep CA-TIMS measurements of closed-system natural zircon samples: Chemical Geology, v. 275, no. 3-4, p. 186-198.

McDougall, I., and Harrison, T.M., 1999, Geochronology and Thermochronology by the ${ }^{40} \mathrm{Ar}{ }^{39} \mathrm{Ar}$ method: New York, NY, Oxford University Press.

Min, K. W., Mundil, R., Renne, P. R., and Ludwig, K. R., 2000, A test for systematic errors in ${ }^{40} \mathrm{Ar} /{ }^{39} \mathrm{Ar}$ geochronology through comparison with $\mathrm{U} / \mathrm{Pb}$ analysis of a 1.1-Ga rhyolite: Geochimica et Cosmochimica Acta, v. 64, no. 1, p. 73-98.

Potts, P. J., 2012, Glossary of Analytical and Metrological Terms from the International Vocabulary of Metrology (2008): Geostandards and Geoanalytical Research, v. 36, no. 3, p. 231-246.

Reiners, P.W., and Ehlers, T.A., 2005, Low-Temperature Thermochronology, Reviews in Mineralogy and Geochemistry, Volume 58; Washington, D.C., The Mineralogical Society of America.

Renne, P.R., Karner, D.B., and Ludwig, K.R., 1998, Absolute ages aren't exactly: Science, v. 282, p. 1840-1841.

Renne, P. R., Mundil, R., Balco, G., Min, K., and Ludwig, K. R., 2010, Joint determination of ${ }^{40} \mathrm{~K}$ decay constants and ${ }^{40} \mathrm{Ar} * /{ }^{40} \mathrm{~K}$ for the Fish Canyon sanidine standard, and improved accuracy for ${ }^{40} \mathrm{Ar} /{ }^{39} \mathrm{Ar}$ geochronology: Geochimica et Cosmochimica Acta, v. 74 , no. 18 , p. 5349-5367. 
Rotenberg, E., Davis, D. W., Amelin, Y., Ghosh, S., and Bergquist, B. A., 2012, Determination of the decay-constant of $87 \mathrm{Rb}$ by laboratory accumulation of $87 \mathrm{Sr}$ : Geochimica et Cosmochimica Acta, v. 85, no. 0, p. 41-57.

Scherer, E., Münker, C., and Mezger, K., 2001, Calibration of the Lutetium-Hafnium clock: Science, v. 293, p. 683-687.

Schoene, B., in press, 3.10 U-Th-Pb geochronology, in Rudnick, R., ed., Treatise on Geochemistry, Volume 3: Oxford, U.K., Elsevier.

Selby, D., Creaser, R. A., Stein, H. J., Markey, R. J., and Hannah, J. L., 2007, Assessment of the ${ }^{187} \mathrm{Re}$ decay constant by cross calibration of Re-Os molybdenite and U-Pb zircon chronometers in magmatic ore systems: Geochimica et Cosmochimica Acta, v. 71, no. 8, p. 1999-2013.

Wasserburg, G. J., Jacobsen, S. B., DePaolo, D. J., McCulloch, M. T., and Wen, T., 1981, Precise Determination of $\mathrm{Sm} / \mathrm{Nd}$ Ratios, $\mathrm{Sm}$ and $\mathrm{Nd}$ Isotopic Abundances in Standard Solutions: Geochimica et Cosmochimica Acta, v. 45, no. 12, p. 2311-2323.

Wendt, I., and Carl, C., 1991, The statistical distribution of the mean squared weighted deviation: Chemical Geology, v. 86, p. 275-285.

Westerhold, T., U. Röhl, Laskar, J., 2012, Time scale controversy: Accurate orbital calibration of the early Paleogene. Geochemistry, Geophysics and Geosystems. 13: Q06015.

Wiedenbeck, M., Alle, P., Corfu, F., Griffin, W. L., Meier, M., Oberli, F., Vonquadt, A., Roddick, J. C., and Speigel, W., 1995, 3 Natural Zircon Standards for U-Th-Pb, LuHf, Trace-Element and Ree Analyses: Geostandards Newsletter, v. 19, no. 1, p. 1-23. York, D., Evensen, N.M., Lopez Martinez, M., and De Basabe Delgado, J., 2004, Unified equations for the slope, intercept, and standard errors of the best straight line: Amer. J. Physics, v. 72, p. 367-375. 
384 Figure 1. Schematic plot illustrating variably accurate and precise data sets. The top panel is 385 a series of bulls eye targets typical of those used to illustrate precision and accuracy, and 386 below are plots more typical of those used in geochronology studies, which plots ratios or 387 dates versus analysis number. Colored rectangles represent single analyses where the height 388 of the bar reflects the 2-sigma uncertainties for that analysis. Y-axis on the left is in $\%$ of the 389 true parent to daughter ratio $(\mathrm{D} / \mathrm{P})$, and on the right is in millions of years.

390

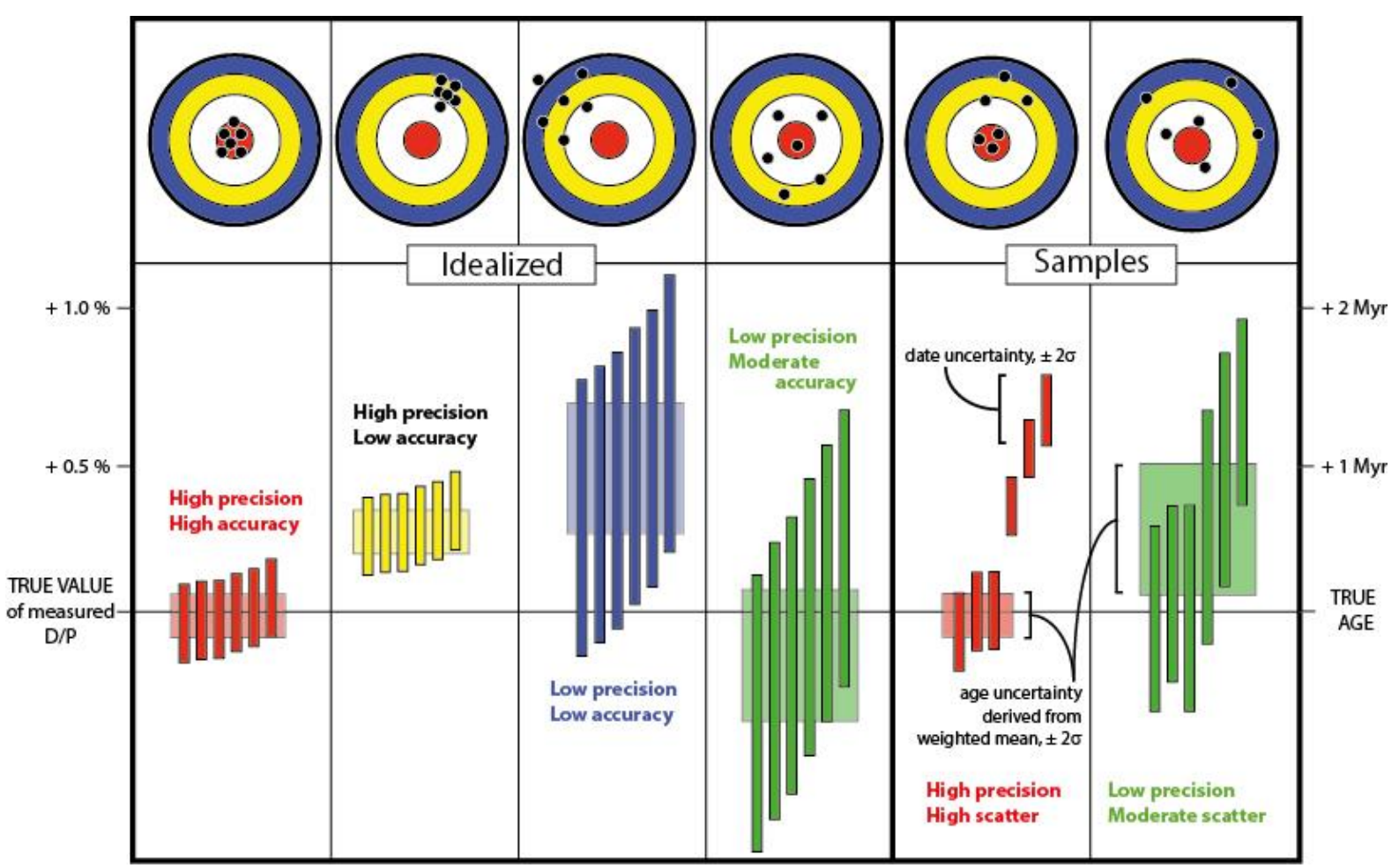


392 Figure 2. Cartoon illustrating how the scale of intra-crystal age zonation, combined with the 393 scale of sampling and the analytical precision, impact the potential accuracy of a date.

394 Mineral zones are color-coded by age with key provided; assumed $>2 \%$ uncertainties for in 395 situ microbeam techniques and $<0.2 \%$ precision for ID techniques. (left) A Mesozoic aged 396 mineral with a Precambrian core; (middle) A Cambrian grain with $300 \mathrm{kyr}$ of crystal growth, and (right) an early Pliocene crystal with $300 \mathrm{kyr}$ of crystal growth. Note that the in this example the volume-age relationship will be biased towards the youngest growth phases, and in real minerals the concentration of the parent nuclide also has to be considered. This figure illustrates that both the spatial resolution of sampling and the temporal precision of the analytical method control whether a single date can be considered accurate.

\begin{tabular}{|c|c|c|}
\hline $\begin{array}{l}1800 \text { Ma core with a } 220 \mathrm{Ma} \\
\text { overgrowth }\end{array}$ & $\begin{array}{l}520 \text { Ma crystal, } 300 \text { kyr }(0.06 \%) \\
\text { crystallization history }\end{array}$ & $\begin{array}{l}\sim 4 \text { Ma crystal, } 300 \text { kyr }(7.5 \%) \\
\text { crystallization history }\end{array}$ \\
\hline $\begin{array}{c}219.9 \mathrm{Mz} \\
220.1 \mathrm{Ma} \\
220.1 \mathrm{Ma}\end{array}$ & $\begin{array}{c}520.0 \mathrm{Ma} \\
520.1 \mathrm{Ma} \\
520.2 \mathrm{Ma}\end{array}$ & \begin{tabular}{|l|l} 
& $3.90 \mathrm{Ma}$ \\
& $4.00 \mathrm{Ma}$ \\
& $4.10 \mathrm{Ma}$ \\
& $4.20 \mathrm{Ma}$ \\
& \\
\end{tabular} \\
\hline $\begin{array}{l}\text { Intra-crystal age variation larger } \\
\text { than analytical precision of } \\
\text { microbeam and ID methods: In- } \\
\text { situ or micro-sampling required }\end{array}$ & $\begin{array}{l}\text { Intra-crystal age variation } \\
\text { unresolvable: whole crystal or } \\
\text { in-situ sample dates are accurate; } \\
\text { weighted mean ages may not be }\end{array}$ & $\begin{array}{l}\text { Intra-crystal age variation exceeds } \\
\text { analytical precision of microbeam } \\
\text { and ID methods: In-situ or micro- } \\
\text { sampling can resolve growth history }\end{array}$ \\
\hline
\end{tabular}


406 An error bar, or confidence interval, illustrates a range of possible values for a measured

407 parameter, like a date. It is a visualization of the uncertainty of the measured parameter, and 408 should always be presented along with an estimate of the probability that the parameter falls 409 within the bounds given. (a) Most high-precision geochronologic data is normally

410 distributed, as shown here in blue, and the confidence level of the error bar corresponds to the 411 area under the curve between its bounds. For instance, the true value of the date has about a $41268 \%$ chance of lying within a one-dimensional $\pm 1 \sigma$ error bar, depicted as a black line below, 413 and about a $95 \%$ chance of lying within a $\pm 2 \sigma$ error bar, depicted as a red bar. While error 414 bars are a simple, succinct way of depicting data, the reader should imagine the shape of the 415 distribution they imply. Thus, there is a higher probability that the true value lies near the 416 center of the error bar than the outside, and importantly there is a finite probability that the 417 true value lies outside the error bar. This is expected about $32 \%$ of the time for a correctly 418 estimated $\pm 1 \sigma$ error bar and about $5 \%$ of the time for a $\pm 2 \sigma$ error bar, and does not imply that 419 the measurement is "wrong." (b) Both random (analytical) and systematic uncertainties may 420 be displayed in the same error bar: In the two analyses depicted, the smaller black bar 421 represents the analytical uncertainty for each analysis, while the larger white bar 422 encompasses the combined random and systematic uncertainties. In the case where the two 423 analyses are from the same dating method (i.e. Lu-Hf, Re-Os, U-Pb, etc.) and the systematic 424 contribution is from decay constants only, the white portion of the error bar needn't be 425 considered: There is a high probability that these two dates are different. The situation 426 changes, however, if the two analyses are from different isotopic systems. In this case, 427 although the analyses agree poorly within analytical uncertainties (black), they agree well 428 when the systematic uncertainties associated with their different decay constants are 429 considered: The dates must be considered indistinguishable (see Renne et al, 1998).

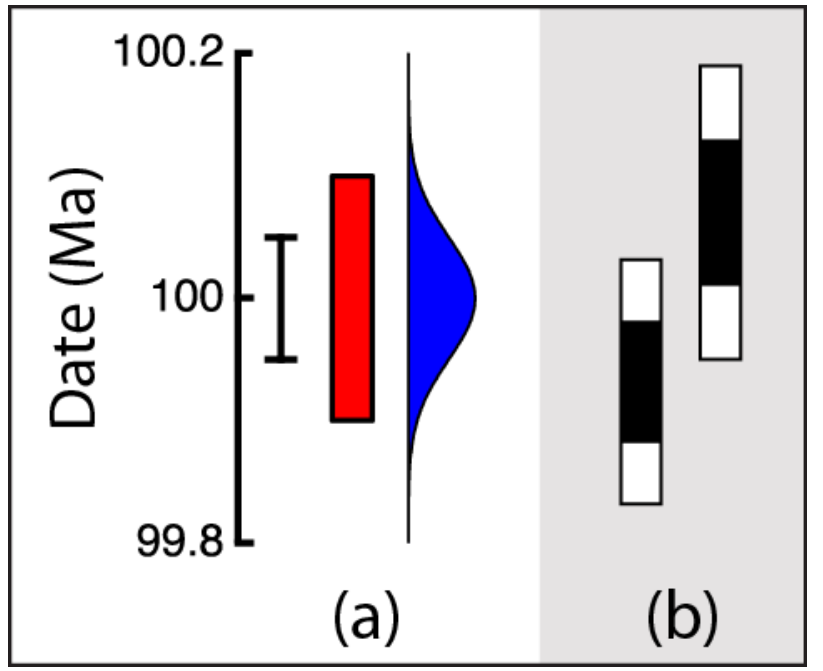

